Journal of Education and Educational Development

7(2), 193-215, 2020

DOI: http://dx.doi.org/10.22555/joeed.v7i2.97

\title{
The Relationship between the Teachers' Expectation on the School Principals' Ethical Behaviors and the School Principals' Ethical Leadership Behaviors
}

\author{
Abdurrahman Ilgan \\ abdurrahman.ilgan@idu.edu.tr \\ Izmir Demokrasi University, Turkey \\ Mustafa Ekiz \\ ekizm001@gmail.com \\ Ministry of National Education, Turkey
}

\begin{abstract}
This study aimed to analyze the teachers' expectations related to the school principals'ethical behaviors and the frequency of the school principals'performing ethical leadership behaviors based on the teachers' perceptions. Data were collected through the Teacher Ethical Expectation Scale (ÖEBÖ) and School Principal's Performing Ethical Leadership Scale (PELBS) which were developed by the researchers for the aim of this research. The sample of the study consisted of 541 participant teachers selected from the population of the teachers working at public schools located in Sakarya, province of Turkey, during the 2018-2019 academic year. According to the teachers' perceptions, it was found that the teachers' expectations of the school principals' ethical behaviors and the frequency of the principals' performing ethical leadership behaviors were quite high. It was also seen that there was a significant positive relationship at a low level because of the path analysis, which was done to predict the school principals' performing ethical behaviors through the teachers' expectations on ethical behaviors. It was concluded that the ethical behaviors from the school principals expected by the teachers as the independent variable were seen to explain $8.6 \%$ of the variance in ethical behaviors performed by the school principals as the dependent variable.
\end{abstract}


Keywords: ethics, ethical behavior, ethical expectation, ethical leadership, path analyses

\section{Introduction}

Ethical leadership is a type of leadership that develops ethical standards to direct employees' behaviors, unifies values and ethical standards, and implements these standards accordingly. In this way, an ethical leader is one who defines the behavioral framework for all social partners in general, and just the employees of the organization exclusively. Ethical leadership is an approach that internalizes a sense of responsibility, makes sharing a common point, and prerequisites moral commitment. It anticipates protecting and respecting each member of the organization from each rank and status. It focuses on respecting people since they are human beings. In this context, ethical leadership plays an essential role in creating higher ethical standards in the organization. Ethical leaders primarily must resist the wrong thing and prevent it. Organizations cannot reach the desired goals through misapplications. Therefore, an ethical leader is like a shield against formal and moral inconveniences, obstacles to organizational success, and performance. For this reason, it could be asserted that the interest in ethical leadership continues briskly in organizational management.

Managerial ethical behaviors, legislations consisting of legal texts like laws, regulations, formal guidelines, circular notes, and formal directives sometimes fail to satisfy the expectations. At this point, ethical principles guide and lead the way for school managers. Ethics in education could be actualized through the right and acceptable ethical attitudes of the school principal as the administrative leader of the school and then of all stakeholders (Aydın, 2013). Instructive ethical principles for administrative ethical sensitivity have mostly been defined in the related academic studies on this issue. According to Aydin (2018), ethical principles which must be followed by the school principals as the leader of a public organization are justice, equality, honesty and righteousness, impartiality, responsibility, human rights, humanism, organizational commitment, the supremacy of law, love, tolerance, secularism, respect, thriftiness, democracy, positive human relations, clarity, human rights, and freedom, remunerating and resisting illegal actions. 
Public management needs to define ethical principles explicitly, create formal ethical frameworks, punish unethical behaviors, and train people in terms of ethical values to be successful in fighting against unethical behaviors. As administrative leaders of an organization, school principals must focus on ethical issues, have higher motivation, and be open to every kind of ethical arguments. In educational organizations that are managed by the leaders with such deeds, ethical problems will decrease in time (Aydın, 2013). The school principals who exhibit ethical leadership characteristics also influence the ethical atmosphere of their organization and their followers as well. The findings of the research show that such kind of influence is an expected situation. However, the principals who fail to perform ethical leadership behaviors and behave just to satisfy personal and organizational ambitions would negatively influence the school climate, social partners, and followers in terms of job satisfaction cynism, etc. This would damage organizational justice, harm people's reliance on organizations, and minimize organizational achievements, reduce the employees' chance of professional improvement (İlğan, 2017).

Educational organizations must endeavor together with the participation of all members and compromise with them considering universal values to specify ethical principles that would direct all the actions and implementations. Ethical principles will help educational organizations overcome misperception such as individuals can only be controlled under formal regulations. It is essential for school principals and other school managers and teachers to define the projections of irrevocable ethical principles for professionals working at educational organizations. It is important to find out about the teachers' expectations of the principals' ethical behaviors and to identify how often principals perform ethical behaviors. Moreover, studies undertaken on this topic would help define ethical principles in the field of education as a profession.

\section{Purpose of the Study}

Ethical principles are one of the prominent aspects of management both in the world and in our country as a part of postmodern educational approaches. The study is important as it revealed the teachers' ethical expectations and identified how frequently the school principals performed such behaviors. The purpose of the study was to find out about teachers' expectations of school principals' ethical behaviors and the influence of their expectations on the school principals' 
performance of these behaviors based on the teachers' perceptions.

\section{Research Questions}

1) What is the level of the teachers' expectations of the school principals' ethical leadership behaviors?

2) Do the teachers' expectations significantly differ based on variables such as gender, age, a subject they teach, educational status, professional seniority, their standards of ethical knowledge, and the school type (preschool, elementary school, middle school, high school) that they work at?

3) How frequently do the school principals perform ethical leadership behaviors based on the teachers' perceptions?

4) Do the teachers' perceptions on ethical leadership behaviors performed by the school principals significantly differ based on the following variables: teachers' gender, age, subject they teach, educational status, professional seniority, their standards of ethical knowledge, and the school type (preschool, elementary school, middle school, high school) that they work at, the school principals' gender, age, seniority in management?

5) Are the teachers' expectations of school principals' ethical behaviors a significant predictor of the frequency of the school principals' performance of ethical behaviors?

\section{Research Design}

\section{Methodology}

This exploratory study aimed to describe public teachers' expectations related to the ethical behaviors of the school principals of the schools where these teachers work and to analyze their expectations in terms of some variables. The relational survey model (Fraenkel et al., 2012) was used for this purpose.

\section{Population and Sample}

The population of the study comprised of 10240 teachers working at public schools located in Sakarya province (Sakarya Directorate of Education, 2018). As the schools were considered as clusters; upon the determination of the schools, the teachers were selected using a simple random sampling technique. In a simple 
random sampling technique, each element creating the population has an equal chance of being selected as the sample. Therefore, each element is focused at the same rate during the analysis (Fraenkel et al., 2012). 541 public teachers made up the sample of the study.

The teachers who formed the sample of the study were asked to score their background of ethical knowledge, the source of it, and their standard of ethical knowledge between $0-100.38(7.0 \%)$ of these 541 did not respond to the type of knowledge they had related to ethical issues. 263 (48.6\%) of the remaining 503 participants responded that they got the knowledge based on 'academic reading', while $63(11.6 \%)$ of them stated that their knowledge on the issue was based mainly on 'in-service-training'. The number of participants who responded that their knowledge was based both on 'academic reading' and 'in-service-training' was 106 (19.6\%). The participants' scores regarding their standard of ethical knowledge expressed by themselves varied between 0 and 100 . The number of the participant who scored himself zero $(0.00)$ point was $1(0.2 \%)$, while $39(7.2 \%)$ participants gave themselves 100 points as exact scores. It was seen that the most commonly used score in which the participants generally rated themselves was $90(20.1 \%)$ and the scores generally varied between $60-95$. The number of participants who did not score their standard of ethical knowledge was $62(11.5 \%)$.

\section{Instrument}

The necessary data of the study was collected through the instruments developed by the researchers themselves. To develop these instruments, firstly, a scale-item-pool was composed of 110 statements related to ethical/unethical behaviors based on the review of the literature along with the expert review. These statements were discussed with the teachers, principals, and specialists, to obtain face and content validity, then the statements which seemed unnecessary and which repeatedly stated similar aspects were excluded from the pool.

The first part of the data collection instrument included demographical variables containing 12 items related to personal information about the participants. The second part of the instrument is comprised of two parts. In one of these parts, which were placed on the left side of the paper, 52 statements scaled the teachers' expectations regarding the principals' ethical behaviors on a five-point-Likert 
scale. On the right side, the teachers were expected to scale using another five-point-Likert scale that asked how frequently their principals performed the ethical behaviors stated in the 52 statements.

The results of the validity and reliability managed on pilot study analysis regarding teachers' ethical expectations related with the school principals' ethical behaviors based on the teachers' perceptions scale (TEES) and the school principals' performing ethical behaviors based on the teachers' perceptions scale (PELBS) were all given in Table 1. KMO coefficients were found to be .97 for both of the scales and the Barlett test was seen to be meaningful $(p<0.01)$ upon the analyses which were done to test the fitness and normality of both of the scales for the factor analysis.

\section{Table 1}

Validity and Reliability Analyses related to Ethical Expectations and Leadership Behaviors

\begin{tabular}{|c|c|c|c|c|c|c|c|}
\hline \multicolumn{4}{|c|}{ Teachers' Ethical Expectations Scale (TEES) } & \multicolumn{2}{|c|}{$\begin{array}{l}\text { Performing Ethical } \\
\text { Scale (PELBS) }\end{array}$} & \multicolumn{2}{|c|}{ Leadership Behaviors } \\
\hline Subscale & Variance & Alpha & Numbe & Subscale & Variance & Alpha & Numbe \\
\hline $\mathrm{s}$ & $\begin{array}{l}\text { Explaine } \\
\text { d \% }\end{array}$ & $\begin{array}{l}\text { Coefficien } \\
\mathrm{t}\end{array}$ & $\begin{array}{l}\mathrm{r} \text { of } \\
\text { Total } \\
\text { Items }\end{array}$ & $\mathrm{s}$ & $\begin{array}{l}\text { Explaine } \\
\text { d \% }\end{array}$ & $\begin{array}{l}\text { Coefficien } \\
\mathrm{t}\end{array}$ & $\begin{array}{l}\mathrm{r} \text { of } \\
\text { Total } \\
\text { Items }\end{array}$ \\
\hline First & 22.47 & .97 & 19 & First & 18.63 & .96 & 18 \\
\hline Second & 19.87 & .96 & 14 & Second & 17.27 & .95 & 13 \\
\hline Third & 11.59 & .90 & 7 & Third & 16.08 & .95 & 12 \\
\hline Fourth & 7.82 & .75 & 4 & Fourth & 6.28 & .81 & 5 \\
\hline Fifth & 7.39 & .88 & 4 & Fifth & 5.77 & .71 & 3 \\
\hline $\begin{array}{l}\text { Total } \\
\text { Scale }\end{array}$ & 69.13 & .98 & 48 & $\begin{array}{l}\text { Total } \\
\text { Scale }\end{array}$ & 64.03 & .98 & 51 \\
\hline
\end{tabular}

As it could be seen in Table 1, TEES was seen to have 48 items in total, four items were removed due to insufficient factor loading, variance explained by the scale was $69.13 \%$ and Cronbach Alpha reliability coefficient was .98 as a result of Exploratory Factor Analyses (EFA). PELBS was seen to have 51 items in total, an item was removed due to insufficient factor loading variance explained by the scale was $64.03 \%$ and Cronbach Alpha reliability coefficient was .98. Based on the findings it could be restated that both TEES and PELBS were reasonably valid and reliable due to scales were developed for the aim of this research quite attentively 
along with that researchers administrated the survey face to face by visiting whole schools.

To analyze the fit indices of TEES which appeared to have 48 items and 5 subscales after EFA, Confirmatory Factor Analysis (CFA) was done via LISREL 9.1. Analyzing the correlations between TEES and subscales correlation coefficients (Lambda) $\chi$ were $=.96, .89, .91, .86$, and .94 respectively and these coefficients were seen to be quite high. Analyzing the fit indices; the index value which appeared to have $5.48 \chi^{2}$ /sd had poor fitting; but, CFI (.98), NFI (.97) and IFI (.98) values seemed to have a good fitting, SRMR value (.053) had acceptable and RMSEA value (.091) was seen to be fair fit as mentioned by McCallum, Browne, and Sugawara (1996) that range of .05 to .10 was considered fair.

Another analysis was done to see the fit indices of PELBS which appeared to have 51 items and 5 subscales after EFA, CFA was done. Analyzing the correlations between TEES and subscales correlation coefficients (Lambda) $\chi$ were $=.84, .93, .94, .89$, and .91 respectively and these coefficients were seen to be quite high. Analyzing the fit indices; the index value which appeared to have 4.97 $\chi 2$ /sd had poor fitting; but, CFI (.98), NFI (.97) and IFI (.98) values seemed to have a good fitting, SRMR value (.068) had acceptable and RMSEA value was (.086) seen fit (McCallum and et. al., 1996).

For the descriptive statistics related with TEES and PELBS mean and standard deviation; Pearson Correlation for the relationship between the teachers' ethical affirmed ethical standards, ethical expectations, and the school principals' ethical leadership behaviors; $t$-test and one way ANOVA for the comparison of the teachers' ethical expectations and the principals' ethical behaviors based on the participants' demographical characteristics; multiple linear regression and path analysis to check the predictability of teachers' ethical expectations for school principals' ethical behaviors were used.

\section{Findings}

Descriptive statistics showing the teachers' expectations related to the school principals' ethical behaviors are given in Table 2 . 


\section{Table 2}

Teachers'Expectations related to the School Principals'Ethical Behaviors

\begin{tabular}{lccc}
\hline \multicolumn{1}{c}{ Subscales } & $\mathrm{N}$ & $\bar{X}$ & $\mathrm{SS}$ \\
\hline $\begin{array}{l}\text { Providing a democratic work atmosphere based on justice, equality, and } \\
\text { dignity }\end{array}$ & 524 & 4.66 & 0.68 \\
\hline Respecting privacy, objectivity, honesty, and trustworthiness & 525 & 4.67 & 0.76 \\
\hline Providing a human centered and quality teaching atmosphere & 527 & 4.71 & 0.66 \\
\hline Avoiding relationships based on self-interest & 521 & 4.53 & 0.93 \\
\hline Communication-based on trust and professional sensibility & 525 & 4.60 & 0.72 \\
\hline Total scale & 524 & 4.65 & 0.72 \\
\hline
\end{tabular}

As seen in Table 2, it was found that teachers' ethical expectations based on their perceptions were quite high in all the subscales as; 'Providing a democratic work atmosphere based on justice, equality and dignity' $(=4.66)$, 'Respecting privacy, objectivity, honesty and trustworthiness' $(=4.67)$, 'Providing a human-centered and quality teaching atmosphere' $(=4.71)$, 'Avoiding relationships based on self-interest' $(=4.53)$, 'Communication-based on trust and professional sensibility' $(=4.60)$.

It was found that the teachers' expectations related to the school principals' ethical behaviors did not significantly differ in any of the subscales of the TEES Scale in terms of demographical characteristics, such as: teachers' gender (1.Female, 2.Male); age groups (1.between 20-30, 2.between 31-40, 3.41 or above); educational status (1.Undergraduate 2.Graduate); teachers' major subjects (1.Preschool and elementary school teachers, 2.Numerical-basic sciences, 3.Verbal-social sciences, 4.Foreign language, 5.Religious education, 6.Vocational subjects); professional seniority (1.0-5 years, 2.6-10 years, 3.11-15 years, 4.16-20 years, 5.21-25 years, 6.26 years or above); school types (1.Elementary school, 2.Middle school, 3.Anatolian high school, 4.Vocational and technical Anatolian high school) and source/type of ethical background (1.Academic reading, 2.In-service-training, 3.Liberal education).

The participant teachers scored their level of ethical knowledge between 0 and 100 based on their self-evaluating. The findings of Pearson Correlation analysis describing the relationship between the teachers' ethical knowledge scores and their expectations related to the school principals' ethical behaviors were given in Table 3. 


\section{Table 3}

Relationship between the TEES Subscale Scores and the Teachers' Ethical Knowledge Standards

\begin{tabular}{lcccccc}
\hline & & $1^{\text {st }}$ & $2^{\text {nd }}$ & Subscale & $3^{\text {rd }}$ & $4^{\text {th }}$ \\
Subscale & Subscale & $5^{\text {th }}$ Subscale \\
\hline Ethical & $\mathrm{R}$ & .044 & .015 & .027 & .039 & .053 \\
knowledge & $\mathrm{P}$ & .356 & .758 & .558 & .409 & .255 \\
score & $\mathrm{N}$ & 440 & 452 & 464 & 451 & 460 \\
\hline$* \mathrm{p}<.05 ; * * \mathrm{p}<.01$ & \multicolumn{7}{c}{} & & & \\
\hline
\end{tabular}

According to the results of Pearson Correlation analysis (Table 3), it was found out that there was a relatively low, positive, and insignificant relationship between the teachers' ethical knowledge scores and the subscales of TEES like; 'Providing a democratic work atmosphere based on justice, equality and dignity' $[(\mathrm{r}=.044, \mathrm{p}>.05)]$; 'Respecting privacy, objectivity, honesty and trustworthiness' $[(\mathrm{r}=.015, \mathrm{p}>.05)]$; 'Providing a human-centered and quality teaching atmosphere' $[(r=.027, p>.05)]$; 'Avoiding relationships based on self-interest' $[(r=.039, p>.05)]$; 'Communication-based on trust and professional sensibility' [( $\mathrm{r}=.053, \mathrm{p}>.05)]$. In other words, there was not a meaningful relationship between the participant teachers' expectations related to the school principals' ethical behaviors and their ethical knowledge scores based on their statements. Descriptive statistics related to the frequency of the school principals' performing ethical behaviors based on the teachers' perceptions were given in Table 4.

\section{Table 4}

School Principals' Performing Ethical Behaviors based on the Teachers' Perceptions

\begin{tabular}{llll}
\hline Subscales & $\mathrm{N}$ & $\bar{X}$ & $\mathrm{SS}$ \\
\hline Respecting privacy, being objective and trustworthy & 532 & 4.27 & 1.09 \\
\hline Professional management ethics & 535 & 4.26 & 0.93 \\
\hline Providing a work atmosphere based on democracy and trustworthiness & 531 & 4.16 & 1.01 \\
\hline Performing like a role model & 533 & 4.12 & 1.16 \\
\hline Considering common public interest during the decision making process & 525 & 3.88 & 1.32 \\
\hline Total scale & 532 & 4.20 & 1.05 \\
\hline
\end{tabular}

It was found out that the behaviors mentioned in the subscales 'respecting privacy, being objective and trustworthy' $(=4.27)$, 'professional management 
ethics' $(=4.26)$ were seen to be performed quite frequently; the behaviors in the subscales 'providing a work atmosphere based on democracy and trustworthiness' $(=4.16)$ and 'performing like a role model' $(=4.12)$ were seen to be performed relatively frequently; lastly, the behaviors mentioned in the 'considering common public interest during decision-making process' subscale were seen to performed quite moderately.

Moreover; in the 'professional management ethics' subscale $[\mathrm{t}(494)=2.37$, $\mathrm{p}<.01]$ of the PELBS scale it was also found as a result of the comparisons between the teachers' considerations related to the frequency of the school principals' performing ethical leadership behaviors based on gender as a variable that female teachers $(=56.33)$ considered the school principals performed ethical leadership behaviors more frequently compared to the male teacher's considerations $(=54.29)$. There were no significant differences in other subscales between the teachers' considerations.

Furthermore, it was found that the teachers' considerations on the frequency of the school principals' performing ethical leadership behaviors did not significantly differ in any of the subscales of the PELBS Scale in terms of demographical characteristics as; teachers' age groups (1.between 20-30, 2.between 31-40, 3.41 or above), educational status (1.Undergraduate 2.Graduate), teachers' major subjects (1.Preschool and elementary school teachers, 2.Numerical-basic sciences, 3.Verbal-social sciences, 4.Foreign language, 5.Religious education, 6.Vocational subjects), professional seniority (1.0-5 years, 2.6-10 years, 3.11-15 years, 4.16-20 years, 5.21-25 years, 6.26 years or above) and source/type of ethical background (1.Academic reading, 2.In-service-training, 3.Liberal education). As for the comparison based on the school type that the teachers worked; in the 'Performing like a role model' subscale, teachers working at elementary schools $(=21.24)$ thought that the school principals performed ethical leadership behaviors more frequently compared to the perceptions of the vocational high school teachers $(=19.66)$. The results of the Pearson Correlation analysis which was done to describe the relationship between the teachers' ethical knowledge scores and the school principals' frequency of performing ethical leadership behaviors were given in Table 5 . 


\section{Table 5}

Relationship between the subscales of PELBS and the Teachers'Ethical Knowledge Scores

\begin{tabular}{|c|c|c|c|c|c|c|}
\hline & & $\begin{array}{l}1^{\text {st }} \\
\text { Subscale }\end{array}$ & $2^{\text {nd }}$ Subscale & $\begin{array}{c}3^{\text {rd }} \\
\text { Subscale }\end{array}$ & $\begin{array}{l}4^{\text {th }} \\
\text { Subscale }\end{array}$ & $5^{\text {th }}$ Subscale \\
\hline \multirow{3}{*}{$\begin{array}{l}\text { Ethical } \\
\text { knowledge score }\end{array}$} & $\mathrm{r}$ & 0.043 & $.123 * *$ & $.106^{*}$ & 0.033 & $.097^{*}$ \\
\hline & $\mathrm{p}$ & 0.379 & 0.009 & 0.03 & 0.49 & 0.042 \\
\hline & $\mathrm{N}$ & 417 & 441 & 415 & 451 & 442 \\
\hline
\end{tabular}

$* \mathrm{p}<.05 ; * * \mathrm{p}<.01$

According to the results of Pearson Correlation analysis (Table 4), it was found out that there were significant positive relationships at low levels between the teachers' ethical knowledge scores and the subscales of PELBS scale as; 'respecting privacy, being objective and trustworthy' $[(\mathrm{r}=.043, \mathrm{p}>.05)]$; 'performing like a role model' $[(\mathrm{r}=.033, \mathrm{p}>.05)]$; professional management ethics $[(\mathrm{r}=.123, \mathrm{p}<.05)]$; providing a work atmosphere based on democracy and trustworthiness $[(\mathrm{r}=.106, \mathrm{p}<.05)]$; considering common public interest during decision making process $[(\mathrm{r}=.097, \mathrm{p}<.05)]$. Furthermore; according to the Pearson Correlation analysis to describe if there were any significant relationships between the school principals' ages and performing ethical leadership behaviors, no significant relationships were found between the school principals' ages and none of the subscales of the PELBS scale.

\section{Path Analysis on the Teachers' Ethical Expectations Predicting the School Principals' Ethical Leadership Behaviors}

In Figure 1, the results of path analysis related to predicting 'the ethical behaviors performed by the school principals' which was the dependent variable of the existing study through the 'expected ethical behaviors by the teachers' which was the independent variable. As it might be seen in Figure 1, factor loads of the indicators related to 'the expected ethical behaviors of the school principals by the teachers' varied between .52 and .81; and the factor loads of the indicators related to 'the ethical behaviors performed by the school principals' varied between .48 , and .79 and they were within reasonable values. Moreover, all of the $t$ values showing the relations from 'ethical behaviors from school principals expected by the teachers' latent variable to the indicators and from 'the ethical behaviors performed by the school principals' to the indicators were all significant. Fit indices related to the model were given in Table 6 . 


\section{Table 6}

Values of the Fit Indices on Prediction of the School Principals' Ethical Behaviors through 'The Ethical Expectations of the Teachers from the School Principals'

\begin{tabular}{lllllllllll}
\hline $\mathrm{X}^{2}$ & SD & P-Value & CFI & NFI & NNFI & AGFI & IF & GFI & SRMR & RMSEA \\
\hline 25744.12 & 4276 & 0.000 & 0.96 & 0.95 & 0.96 & 0.47 & 0.96 & 0.50 & 0.060 & 0.096 \\
\hline
\end{tabular}

As could be seen in Table 6, CFI and IFI showed well; NFI, NNFI, and SRMR showed reasonable fit values; but X2 / sd = 6; AGFI, GFI, and RMSEA showed bad fit values. McCallum and et. al., (1996) as mentioned above suggest that RMSEA ranged between. 05 to .10 is acceptable. Taking all the values between the model and data, and the fit indices into consideration it could be stated that the model had acceptable indices.

Considering the values in Figure 1, it was seen that the standardized coefficient between the school principals' ethical behaviors expected by the teachers and ethical behaviors performed by the school principals was $\chi=0.29$, it was positive and at a low level. According to the findings, a single unit increase in the teachers' expectations of the school principals' ethical behaviors would cause a .24 point increase in the level of the school principals' performing ethical behaviors. The regression equation regarding the model was:

Expected Ethical Behaviors $=0.29 *$ Performed Ethical Behaviors, Error Variance $=0.91 ; \mathrm{R} 2=0.86$. 'The ethical behaviors from the school principals expected by the teachers' which was the independent variable explained $8.6 \%$ of the variance in 'ethical behaviors performed by the school principals' which was the dependent variable. It could be stated that the model had a lower explanation rate for the dependent variable. 


\section{Figure 1}

Path Analysis Related With Predicting the Ethical Behaviors Performed by the School Principals

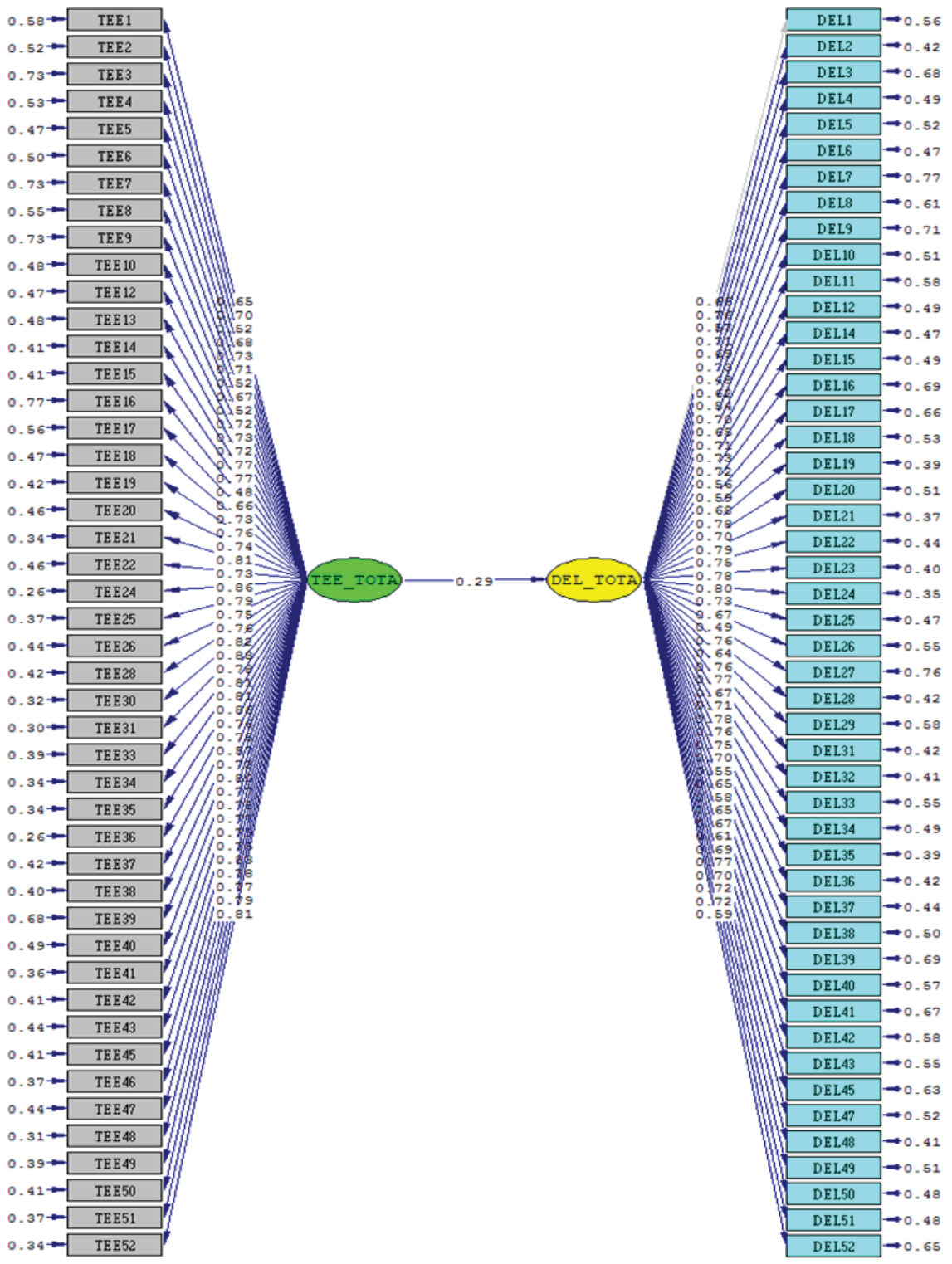

Chi-Square=25744.12, $d f=4276, \mathrm{P}-\mathrm{value}=0.00000$, RMSEA=0.096 


\section{Discussion and Conclusion}

In this part of the study the results of the existing research and the discussion and considerations based on the results and the related literature, together with the suggestions within the context of the findings are provided.

\section{On the Teachers' Ethical Expectations}

It appeared as a result of the study that the teachers' expectations of the school principals' ethical behaviors were quite high $(=4.65)$. Additionally; as a result of the evaluation of the subscales of the TEES scale in term of mean, the sequence of the subscales from the highest to the lowest one was "providing a human-centered and quality teaching atmosphere $(=4.71)$ ', 'respecting privacy, objectivity, honesty and trustworthiness', 'providing a democratic work atmosphere based on justice, equality and dignity', 'communication-based on trust and professional sensibility' and 'avoiding relationships based on self-interest $(=4.53)^{\prime}$ '. Girgin (2005) found out that elementary school principals met the teachers' expectations 'rarely' in decision making, planning, communication, influencing and evaluation processes; 'mostly' in organization and coordination processes. Toker (2007) found that the teachers expected leadership behaviors from the school principals 'mostly' in the educational supervision subscale, but they experienced such behaviors 'rarely'. In the study by Güzelce (2009) to reveal the teachers' expectations about the school principals' decision-making process and the actual situation, it was seen that the participants' total scores were scaled as 'occasionally' for the actual situation, 'always' for the expectations.

The participant teachers were asked, within the scope of the study, to rate their knowledge about ethics between 0 and 100 regarding the definition of ethics, ethical principles, ethical principles for the teaching profession, ethical fields, ethical leadership, etc. The number of participants who rated themselves zero (0.00) point was $1(0.2)$, while 39 (7.2) participants gave themselves 100 points as exact scores. It was seen that the most commonly used score in which the participants generally rated themselves was 90 (20.1\%). The teachers' higher level of knowledge on the issue also influenced the realization of an active and efficient ethical atmosphere. According to the Pearson correlation analysis results, there were positive relations between the teachers' standard of ethical knowledge and their expectations of ethical behaviors from the school principals, but these 
relations were seen to be at lower levels and insignificant.

\section{On the School Principals' Ethical Leadership Behaviors}

As a result of the study, it was found that the school principals frequently performed ethical leadership behaviors during school management according to the teachers' perceptions $(=4.20)$. The sequence of PELBS subscales based on the mean was; 'respecting privacy, being objective and trustworthy' (=4.27), 'professional management ethics', 'providing a work atmosphere based on democracy and trustworthiness', 'performing like a role model', 'considering common public interest during decision-making process' (=3.88). Similar findings related to the school principals' performing frequent ethical leadership behaviors were seen in some other studies as well (Akçekoce \& Bilgin, 2016; Gözüm, 2019; Küçüksüleymanoğlu \& Çelik, 2014; Sağır \& Tutkun, 2017; Sağlam \& Emirbey, 2017; Uranbey, 2018). The teachers' higher levels of awareness rates related to the school principals' performing ethical leadership behaviors give the impression that educational organizations are getting some kind of ethical character over time. It is possible to highlight that teaching staff who have ethical standards adequately with different types of knowledge on ethical issues and school principals who internalize ethical leadership and act accordingly help the realization of this atmosphere.

Another comparison between the teachers' perceptions related to the frequency of the school principals' performing ethical behaviors was based on the teachers' gender. As a result of the comparison in the 'professional management ethics' subscale of PELBS, it was seen that female teachers perceived the school principals performed ethical leadership behaviors more frequently compared to the male teachers' perceptions. There were no significant differences in the other subscales between the teachers' perceptions considering gender as a variable. In the sample studies carried out by Baştuğ (2009), Çınar (2019), Durmuş (2015), Ertürk (2012), Hendekçi et al. (2018), İskele (2009), Küçüksüleymanoğlu et al. (2014), Selimoğlu (2008) and Turhan (2007) concluded that the perceptions of the teachers who worked at public schools related with the principals' ethical leadership behaviors did not differ based on the teachers' gender. Studies by Bostanc1 \& Yolcu, (2011), Karagöz (2008), Sağlam et al. (2017) and Topuzoğlu (2009) found similar results to the findings of this study that in one of the subscales, female teachers perceived that school principals performed ethical leadership behaviors more frequently compared to the male teachers' perceptions. Dissimilarly, Selimoğlu 
(2008) found results in favor of the male teachers in terms of gender variables in the 'tolerance' subscale of his ethical leadership study. Despite differing results concerning gender variables, the findings of the existing study are similar to the findings in studies in the related literature.

According to the Pearson correlation analysis, it was found out that there were significant positive relationships at a lower level between the second subscale of PELBS 'professional management ethics' ( $\mathrm{r}=.123)$, the third subscale 'providing a work atmosphere based on democracy and trustworthiness' $(r=106)$, and the fifth subscale 'considering common public interest during decision-making process' $(r=.097)$ and the ethical knowledge scores of the participant teachers.

It could be restated that there were positive significant relations at a lower level between three subscales of PELBS and the teachers' ethical knowledge scores (between 0 and 100). Therefore, it could be expressed that teachers' higher ethical knowledge levels would increase the possibility of school principals' performing ethical leadership behaviors. Demirel, et al. (2013) found in the study which researched the relationship between the influence of ethical leadership on the organization and normative commitment to the management positive correlation at a medium level between two variables.

\section{Comparison of the School Principals' Ethical Leadership Behaviors' Demographical Variables}

In the study, another comparison was made regarding the teachers' perceptions of the ethical behaviors performed by principals based on demographical variables. It was found out that the ethical behaviors performed by the principals did not differ based on gender in all of the subscales of PELBS ( $p>$ $.05)$. In other words, the teacher perceived that female and male school principal performed ethical leadership behaviors at similar rates.

Positive relationships at a lower level between the school principals' ages and the scores of the subscales of PELBS as; 'respecting privacy, being objective and trustworthy', 'providing a work atmosphere based on democracy and trustworthiness', 'performing like a role model', 'considering common public interest during decision-making process'. As for 'professional management ethics', it was found that there were negative relationships between the scores of the 
subscale and the school principals' ages. That is to say, there were not significant relationships between the frequency of the school principals' ethical behaviors and their ages. In general, the teachers perceived that the school principals' ages did not influence the frequency of the school principals' performance of ethical behaviors.

In all the subscales of PELBS, ethical behaviors performed by the school principals significantly differed based on the principals' subjects. In the 'respecting privacy, being objective and trustworthy' subscale the principals whose main subjects were preschool and elementary school, numerical/basic sciences, verbal/social sciences performed ethical leadership behaviors more frequently than the ones whose main subjects were foreign language; the principals whose main subjects were preschool and elementary school, numerical/basic sciences performed ethical leadership behaviors more frequently than the ones whose main subjects were vocational. 'In professional management ethics' subscale once again the principals whose main subjects were preschool and elementary school, numerical/basic sciences, verbal/social sciences performed ethical leadership behaviors more frequently than the ones whose main subjects were foreign language; the principals whose main subjects were preschool and elementary school, numerical/basic sciences performed ethical leadership behaviors more frequently than the ones whose main subjects were vocational. In the 'Providing a work atmosphere based on democracy and trustworthiness' subscale the principals whose main subjects were numerical/basic sciences performed ethical leadership behaviors more frequently than the ones whose main subjects were foreign language; the principals whose main subjects were preschool and elementary school, numerical/basic sciences performed ethical leadership behaviors more frequently than the ones whose main subjects were vocational. Baştuğ, (2009) as well stated that the teachers' perceptions of the school principals' performing ethical behaviors differed based on the school principals' subjects in climatic, behavioral, and decision-making ethics subscale.

\section{Predicting the Ethical Behaviors Performed by the School Principals through the Expected Ethical Behaviors by the Teachers}

The prediction related to the subscales of the School Principals Ethical Leadership Behavior Scale (PELBS; dependent variable) through the Teachers' Ethical Expectations Scale (TEES, independent variable) was analyzed using 
multilinear regression and path analysis, and the results are given below.

There was a positive and significant relationship at a low level between TEES and 'respecting privacy, being objective and trustworthy' which the first subscale of PELBS is; it explained $12 \%$ of the total variance in the subscale. According to t-test results related to the sign of the regression coefficients, it was found out that just 'respecting privacy, objectivity, honesty and trustworthiness' which is one of the subscales of TEES was a significant predictor of 'respecting privacy, being objective and trustworthy' as one the sub-scales of PELBS.

Secondly, there was a positive and significant relationship at a low level between TEES and 'professional management ethics' which is the second subscale of PELBS; it explained $8 \%$ of the total variance in the subscale. According to t-test results related to the sign of the regression coefficients, it was found out that none of the subscales of TEES is the significant predictor of 'professional management ethics'.

Thirdly, there was a positive and significant relationship at a low level between TEES and 'providing a work atmosphere based on democracy and trustworthiness' which is the third subscale of PELBS; it explained $6 \%$ of the total variance in the subscale. According to t-test results related to the sign of the regression coefficients, it was found out that none of the subscales of TEES is the significant predictor of 'providing a work atmosphere based on democracy and trustworthiness'.

Furthermore, there was a positive and significant relationship at a low level between TEES and 'performing like a role model' which is the fourth subscale of PELBS; it explained $14 \%$ of the total variance in the subscale. According to t-test results related to the significance of the regression coefficients, it was found out that just 'avoiding relationships based on self-interest' is a significant predictor of 'performing like a role model'.

Lastly, there was a positive and significant relationship at a low level between TEES and 'considering common public interest during decision-making process' which is the fifth subscale of PELBS; it explained $12 \%$ of the total variance in the subscale. According to t-test results related to the significance of the 
regression coefficients, it was found out that 'providing a democratic work atmosphere based on justice, equality and dignity', 'respecting privacy, objectivity, honesty and trustworthiness', 'avoiding relationships based on self-interest' which are the subscales of TEES are the significant predictors of 'considering common public interest during decision-making process'.

According to the results of the path analysis related to the prediction of 'ethical behaviors performed by the school principals' which was the dependent variable through 'the ethical behaviors from the school principals expected by the teachers' which was the independent variable, it was seen that the standardized coefficient between the school principals' ethical behaviors expected by the teachers and ethical behaviors performed by the school principals was $\chi=0.29$, it was positive and at a low level. Depending on the findings, it could be stated that a single unit increase in the teachers' expectations of the school principals' ethical behaviors would cause a .24 point increase in the level of the school principals' performing ethical behaviors. 'The ethical behaviors from the school principals expected by the teachers' as the independent variable was seen to explain $8.6 \%$ of the variance in 'ethical behaviors performed by the school principals' as the dependent variable. Therefore, it could be specified that the explanation rate of the dependent variable through the model was at a low level.

\section{Recommendations}

I. It might be suggested that the results showing the increase in the teachers' ethical knowledge scores positively influenced the school principals' ethical leadership behaviors, the teachers' expectations related to the school principals' ethical behaviors, and the school principals' not frequently performing ethical behaviors should be taken into consideration by educational administrators. In this context, the people with the desired ethical qualifications (principles, codes, values, and rules) who are capable of meeting the teachers' expectations should be appointed as school principals.

II. Educational activities should be initiated to improve the teachers' ethical knowledge types and levels regarding educational processes and to improve their awareness of the issue. Activities could include academic reading like books, articles, and stories; programs like films, 
animations; activities like seminars, panels, conversations, debates, etc. This would be beneficial for the teachers who avoided declaring their views on their ethical knowledge standards, who declared that they gained ethical knowledge-based just on a source, or for the ones whose ethical knowledge scores seemed low.

III. It might be suggested that another study could be undertaken to identify the factors which provided the preschool principals' performing frequent ethical leadership behaviors in the 'Performing like a role model' subscale of PELBS, and the factors which caused vocational school principals' performing less frequent ethical leadership behaviors.

IV. To get more realistic results, to analyze the teachers' ethical knowledge levels accurately, the teachers, could be asked ethical questions related to the cognitive domain.

\section{References}

Akçekoce, A., \& Bilgin K.U. (2016). The principals' leadership styles and teachers' performance. Journal of Contemporary Administrative Sciences, 2(2) 1-23. Altunay, E., \& Özgözcü, S. (2016). The effects of school directors' leadership on teachers' organizational attitudes: A meta-analysis study. Journal of Social Sciences Manisa Celal Bayar University, 14(4), 259-294.

Argon, T. (2016). Favoritism behaviors of primary school managers from teachers' point of view. Kastamonu Journal of Education, 24(1), 233-250.

Atlar, Y. (2015). Examining school administrators' ethical leadership behaviour according to teachers. [Unpublished dissertation], Zirve Üniversity.

Aydın, İ. (2006). Ethics in education and teaching. PegemAkademi.

Aydın, İ. (2013). Teaching supervision: Situation determination, evaluating and developing. PegemAkademi.

Aydın, İ. (2017). Administrative, professional and organizational ethics. Pegem Akademi.

Aydin, İ (2018). Publich ethics. https://www.tbmm.gov.tr/ etik_komisyonu/belgeler/makale_KamudaEtik-InayetAydin.pdf

Baştuğ, İ. (2009). Teachers' perspectives about the primary school leaders on ethical leadership behaviours: Konya sample 's. [Unpublished dissertation]. Selçuk University. 
Bostanc1, A. B., \& Yolcu, H. (2011). The compliance level of primary school administrators to ethical principles while evaluating the teachers' performances. Journal of Human Sciences, 8(1), 922-940.

Çelik, N., \& Küçüksüleymanoğlu, R. (2014). Relationship between ethical leadership characteristics of secondary school administrators and organizational commitment of teachers. Journal of World of Turks, 6(3) $19-43$.

Çınar, U. (2019). Analysis of vocational and technical high school administrators' ethical leadership behaviors according to views of teacher. [Unpublished master dissertation]. Maltepe University.

Demirel, E., Derin N., \& K. Çakınberk, A. (2013). Examining relationship between ethical leadership and normative commitment in terms of social exchange theory. In M. K. Demirci, G. E. Gümütştekin, N. D. E. Özler ve C. G. Atalay (Eds.). 21st National administration and organization conference'book (pp. 686-693). Nobel Yayınevi.

Durmuş, M. (2015). The examination of public manager's level of showing ethical leadership behaviour in the aspect of public servant perception: Sample of Kocaeli university. [Unpublished doctoral dissertation]. Kocaeli University. Emirbey, A. R., \& Sağlam, A. Ç. (2017). The relatıonshıp between etıchal leadershgip behaviours of school administrators and teacher's motivation. The Journal of Turks Islam World Social Sciences, 4(12), 92-104.

Ertürk, H. (2012). A research on the ethical leadership level of school principals: Uşak city sample. [Unpublished master dissertation]. Uşak University.

Eryılmaz, B. \& Bricikoğlu H. (2011). Accountability and ethics in public administration. Turkish Journal of Business Ethics, 4(1), 19-45.

Fraenkel, J. R., Wallen, N. E., \& Hyun, H. H. (1993). How to design and evaluate research in education (Vol. 7). McGraw-Hill.

Girgin, K. (2005). The level of meeting the teachers' expectation by the administrators of education process view while forming an effective school. (Unpublished master dissertation). Dumlupınar University.

Gözüm, P. (2019). A research on teachers in terms of job satisfaction and ethical climate. Journal of Economics and Administrative Sciences Faculty of Mehmet Ekif Ersoy University, 6(1), 230-245. https://dx.doi.org/10.30798/makuiibf.516674

Güzelce, A. (2009). Primary school teachers in the task manager of the perception and expectations regarding decision- making process. (Unpublished master 
dissertation). Maltepe University, İstanbul.

İlğan, A. (2017). Professional development and supervision of teachers: Learning teachers succeed students. An1 Publishing.

İskele, A. (2009). The effect of primary school principals? Ethical leadership behaviour on creative climate in primary schools. (Unpublished doctoral dissertation). Akdeniz University.

Karagöz, A. (2008). The relationship between elementary and secondary school teachers? organizational committments and administrators? ethical leadership roles as perceive of teachers. [Unpublished master dissertation]. Yeditepe University.

MacCallum, R. C., Browne, M. W. \& Sugawara, H. m. (1996). Power analysis and determination of sample size for covariance structure modeling, Psychological Methods, 1(2), 130-149.

Polatcan, M., \& Cansoy R. (2019). The relationship between school principals' leadership and teachers' organisational commitment: a systematic review. Bartın University Journal of Faculty of Education, 8(1), 1-31.

Sağır, M., \& Tutkun B. (2017). The relationship between ethical leadership behaviors of school principals' self -efficacy of teachers. Journal of Social Sciences Duzce University, 7(2), 44-68.

Sakarya Directorate of Education. (2018, September 20). Education statistics of Sakarya province, Governor of Sakarya Province. https://sakarya.meb.gov.tr

Selimoğlu, O. (2008). Obedience of headmasters of burs high schools to ethics principles from the view of the vocational high school teachers. [Unpublished master dissertation]. Yeditepe University.

Toker, T. (2007). Classroom teachers' expectations related to the instructional leadership behaviors of primary school principals and the level of fulfillment of those expectations. [Unpublished doctoral dissertation]. Hacettepe University.

Topuzoğlu, A. P. (2009). Ethical leadership in terms of demographic characteristics of the school administrator features. [Unpublished master dissertation]. Maltepe University.

Turhan, M. (2007). The effect of ethical leadership behaviors of high school and vocational high school principals on social justice in schools. [Unpublished doctoral dissertation]. Firat University.

Uranbey, E. (2018). The impact of ethical leadership on organizational 
commitment and intent to leave work. [Unpublished master dissertation]. Başkent University.

\section{Citation of this Article:}

Ilgan, A., \& Ekiz, M. (2020). The relationship between the teachers' expectation on the school principals' ethical behaviors and the school principals' ethical leadership behaviors. Journal of Education and Educational Development. 7(2), 193-215. 